\title{
ARROLAMENTO DAS FONTES HISTÓRICAS DE ITAPETININGA E REGIÃO CIRCUNVIZINHA.
}

\section{INTRODUÇÃO HISTÓRICA.}

O município de Itapetininga está situado na zona fisiográfica denominada: "Campina de Sudeste". Dista da capital estadual 144 quilômetros em linha reta. Limita-se com os seguintes municípios: Capão Bonito, Burí, Angatuba, Guareí, Tatuí, Araçoiaba da Serra, Sarapú, Pilar do Sul e São Miguel Arcanjo. Sua origem histórica, ao contrário de muitas outras localidades, tem data certa: 4 de novembro de 1770. Mais ainda. Foi seu fundador e administrador Simão Barbosa Franco, credenciado oficialmente pelo próprio governador da capitania de São Paulo (o morgado de Mateus). Decorrido apenas um ano, a 4 de fevereiro de 1771, o próspero povoado foi elevado à Vila dc Nossa Senhora dos Prazeres de Itapetininga. Sòmente em 1655, passou à categoria de cidade, em decorrência da Lei Provincial $n .^{\circ} 5$ de 13 de março dêsse mesmo ano.

O Brasão de Armas da Cidade de Itapetininga foi criado pela Lei Municipal n. ${ }^{\circ} 113$ de 19 de julho de 1950.

Vinculada à criação do povoado, a padroeira é Nossa Senhora dos Prazeres, festejada durante o mês de maio.

Dentre as festas folclóricas guardadas pela tradição, merecє destaque a "cavalhada", ou mais especificamente a "carreira dos cavalos", descrita pelo Prof. Alceu Maynard Araújo, em seu valioso livro Poranduba Paulista.

Cidade aprazível e acolhedora, Itapetininga é um centro estudantil e cultural dos mais expressivos do Estado. O número e o alto nível de suas escolas, fêz com que lhe dessem o epíteto de "Atenas do Sul", como à tradicional cidade sul mineira de Alfenas, que também é conhecida como "Atenas mineira" e São Luís do Maranhão, cognominada "Atenas Brasileira".

Dentre os filhos ilustres de Itapetininga desejamos destacar o grande Venâncio Ayres, figura exponencial de republicano, que merece uma biografia à parte, a fim de ser reverenciado 
como merece. Destacamos ainda o dr. Júlio Prestes de Albuquerque, não apenas pelo fato de haver sido governador do Estado, de 1927 a 1930 e presidente-eleito da República a 34-X-1930, cargo que a Revolução de 1930, vitoriosa, impediu que êle tomasse posse, mas por uma outra razão mais profunda e mais. significativa: a posição assumida quando da epopéia constitucionalista de 1932. Conforme atesta uma carta, manuscrita, datada de Liverpool, o dr. Júlio Prestes escreveu a seu filho Fernando, pedindo-lhe providências imediatas no sentido de seu retôrno ao Brasil, pois irmanado com os paulistas queria êle, trocando a presidência da República por um fuzil, lutar apenas como soldado e na vanguarda, pela constitucionalização do Brasil. Ésse impressionante documento histórico, ainda inédito, foi apresentado e comentado pelo historiador Aureliano Leite em palestra recente, na Sociedade de Estudos Históricos (31-X-61), subordinada ao título: "A Revolução de 1932: causa e objetivo". Ainda mais, o fato foi confirmado pelo Prof. Waldemar Ferreira, presente à mesma sessão cultural da SEH, naquela época secretário do Movimento - e premier do govêrno revolucionário, na feliz expressão de Aureliano Leite - que foi quem lhe impediu a efetiva concretização da idéia, receioso de uma exploração política, de conseqüências imprevisíveis, caso se efetivasse o desejado retôrno (1).

Apenas como um final a êste preâmbulo modesto à história dá cidade de Itapetininga, desejamos alertar tanto as autoridades, como aos estudiosos vinculados a essa cidade, que no Departamento do Arquivo do Estado, - a repartição pública mais antiga de São Paulo (remonta a 1721) e talvez a mais bem organizada da capital - há numerosos e valiosos documentos, ainda inéditos, sôbre Itapetininga, que representam um filão $\mathrm{d} \epsilon$ riquezas imprevisíveis. Mesmo na própria localidade, nos arquivos públicos e particulares, há documentos preciosos que precisam ser divulgados e estudados. Comprovando nossa afirmação, lá existe o arquivo dos descendentes de Remíjio de Bellido, moradores na cidade, que reflete sua fecunda vida de estudioso, historiador, filatelista e amigo dos grandes vultos: seus contemporâneos, com os quais se correspondia, deixando um precioso acervo que apenas folheamos e do qual destacamos duas cartas, inéditas, que lhe escreveram dois nomes ex-

(1). - Carta a ser publicada na Revista de História n.o 51, julho-setembro de 1962, no resumo da conferêncla pronunciada pelo Dr. Aureliano Leite ná Sociedade de Estudos Históricos (Nota da Redaçáo). 
ponenciais da intelectualidade brasileira: Ruy Barbosa e Capistrano de Abreu e que, por gentileza do Sr. Dagoberto Guimarães, neto de Remíjio Bellido, estampamos em anexo.

Itapetininga parece remontar ao final do século XVII ou comêço do século XVIII, pois, nos primórdios de 1700 , a vila de Sorocaba era o local para onde convergiam aquêles que negociavam com gado.

Havia um "pouso" às margens do Rio Itapetininga, distando 12 léguas da então vila de Sorocaba, procurado por aquêles que demandavam ou provinham do Sul do Brasil.

Esse "pouso" pode ser identificado no atual bairro Pôrto. Dentre as pessoas que ali estiveram inúmeras vêzes, no decorrer do século XVIII, podemos citar Domingos José Vieira, natural de Braga (Portugal). Homem trabalhador e de espírito empreendedor, Domingos José Vieira resolveu, com alguns companheiros, fixar-se nas terras do "pouso" e ali iniciar algumas plantações.

Em breve surgia um pequeno arraial.

Decorridos alguns anos, as matas foram sendo dizimadas e a terra perdendo a fertilidade.

Resolveu, então, José Vieira procurar um local onde as condições de vida fôssem mais favoráveis ao hómem, idéia que encontrou eco entre outros moradores.

Fundaram, então, em local não muito distante do antigo "pouso", um pequeno arraial.

Por essa ocasião, novos povoadores, sob a direção de Pascoal Leite de Moraes, foram chegando e passaram a residir no local que havia sido abandonado por Domingos José Vieira.

Os novos habitantes dedicavam-se à agricultura e à pecuária. Assim, o velho e abandonado "pouso" voltou à vida, desenvolveu-se e prosperou.

Com o crescente desenvolvimento dos dois povoados, rivalidades foram surgindo entre os dois chefes, que passaram a disputar a criação oficial da Vila. Tais notícias foram ter a Sorocaba e dali, pouco depois, chegavam à sede da então Capitania de São Paulo.

Em decorrência, o governador da Capitania de São Paulo, Capitão General Luís Antônio de Sousa Botelho de Mourão, Morgado de Mateus, ordenou a Simão Barbosa Franco, em 17 
de abril de 1768 que servisse de fundador e administrador da nova povoação nas campinas de Itapetininga, visto que já o era de "Ubutucatu".

Assim o fêz. A 6 de julho do mesmo ano e a 4 de novembro de 1770 teve lugar o ato do levantamento do pelourinho com missa solene e coube ao Doutor Ouvidor Geral da Comarca e das Câmaras de Sorocaba e de Itapetininga verificar o grande cuidado e zêlo com que se houve Simão Barbosa na criação da nova Vila e levantamento do pelourinho.

A 4 de fevereiro de 1771 prestou êle juramento de Juiz Ordinário da Vila de Nossa Senhora dos Prazeres de Itapetininga, perante o Ouvidor e Corregedor da Comarca de São Paulo, Doutor Salvador Pereira da Silva, e a 3 de março seguinte deferiu juramento a outro Juiz Ordinário, o Alferes Domingos José Vieira e aos Oficiais da Nova Câmara, José Rodrigues Guimarães, Miguel Fernandes de Abreu, Sebastião Rodrigues de Quevedo e Bernardo José Tavares, procurador:

A requisição da Câmara assim constituída, tendo por escrivão João de Madureira Calheiros, em representação de 17 de março de 1782 e por Carta Patente do Capitão General Francisco da Cunha Menezes, de 26 de agôsto de 1785, confirmada por Carta da Rainha Dona Maria I, de 17 de outubro do mesmo ano, foi nomeado $10^{\circ}$ Capitão-mor de Itapetininga, Salvador de Oliveira Leme, morador de Sorocaba.

Por proposta da mesma Corporação e Patente do Capitão. General Bernardo José de Lorena, de 3 de dezembro de 1789, foi nomeado $1 .^{\circ}$ Sargento-mor da Vila, Salvador de Oliveira Aires.

Ao território da nova Vila foi anexado o do Arraial de Paranapanema a pedido dos respectivos moradores, por despacho do Capitão General Dom Luís, de 15 de abril de 1771.

Conservou-se como vila até que foi elevada à categoria de Cidade, com a mesma denominação pela Lei Provincial n. ${ }^{\circ} 5$ de 13 de março de 1855. Do seu território foram desmembradas as seguintes povoações: Tatuí, Botucatú, Paranapanema, Sarapuí e São João Batista do Guaré, municípios separados, pertencendo-lhe ainda a importante freguesia do Espírito Santo da Boa Vista e as do Bom Jesus de Alambarí e São Miguel Arcanjo.

Atualmente possui os seguintes distritos de Paz: Itapetininga, com dois sub-distritos, o $1 .^{\circ}$ Itapetininga e o $2 .^{\circ}$ Aparecida do Sul, nos têrmos do Decreto n. ${ }^{\circ} 9.073$, de 31 de março de 1938, modificado pelo Decreto-Lei n. 14.334 , de 30 de novembro de 1944; Alambarí, Morro Alto e Gramadinho. 
O Decreto-Lei n. ${ }^{\circ} 14.334$, de 30 de novembro de 1944 transformou as Zonas em Sub-Distritos (2).

\section{O PROBLEMA DO NOME.}

Itapetininga. O vocábulo é de origem tupi-guaraní, não há e nem pode haver dúvidas a êsse respeito. Segundo Teodoro. Sampaio, Itapetininga significa pedra enxuta ou laje sêca, pois, argumenta, deriva de Itape - corruptela de Itapeva, que significa pedra, laje; e tininga que por sua vez significa sêca, enxuta.

\section{FONTES MANUSCRITAS E IMPRESSAS EXISTENTES NO DEPARTAMENTO DO ARQUIVO DO ESTADO DE S. PAULO.}

A semelhança do que ocorre com outras localidades paulistas, acha-se devidamente recolhida e catalogada no Departamento do Arquivo do Estado, uma preciosa documentação sôbre o passado histórico de Itapetininga, além de registos civis, imobiliários, requerimentos, mapas educacionais - pois. o Departamento do Arquivo subordinava-se à Secretaria da Educação do Estado - até o último lustro.

De acôrdo com a estrutura da própria repartição, na Secção Histórica estão catalogados, restaurados e acondicionados em milhares de latas de alumínio, próprias e funcionais, os documentos referentes aos tempos coloniais e imperiais. $\mathrm{Na} \mathrm{Sec}-$ ção Administrativa, os mais recentes, isto é, relacionados com a éra republicana e, na Biblioteca: livros e coleções de jornais.

\section{I. - NA SECÇÃO HISTÓRICA.}

Os estudiosos do passado erudito de Itapetininga, podem encontrar na secção históriça Códices instrumentando maços de população, do período de 1768 a 1846 ininterruptamente, ofícios diversos das Câmaras e autoridades locais ao Capitão-mor da Capitania e ao Governador da Província de São Paulo, de

(2). - Almelda (Aloísio). - Itapetininga, in "O Correio Paulistano". São Paulo, edição de julho de 1954 e Editorial, Itapetininga, a Atenas do Sul, in "O Diário de São Paulo". Sāo Paulo, edição de 3 de junho de 1950. Enciclopédia dos Municípios Brasileiros. Rio de Janeiro, 1957. Vol. XXVIIr, págs. $446-450$. 
1821 a 1888. Ainda, livros de registos de terras de Itapetininga e arredores, em decorrência da lei do tombamento de 1854 .

a). - Maços de População.

Os maços de população de Itapetininga ocupam 6 latas de alumínio, sendo que há mais uma lata correspondente ao ano de 1827 para Itapetininga e Portão.

A distribuição dos Códices está em ordem cronológica e são êles identificados por uma ficha branca, assim escrituradas:

“T. C. (Tempos Coloniais) 1768-1769. População de Itapetininga. Caixa - 65".

A título de curiosidade vale a pena lembrar que êsses "maços de população", eram levantamentos visando instruir o govêrno da.Capitania e depois da então Província de São Paulo se bem que realizados sob o prisma militar, instrumentam a própria pulsação da vida local - e foram na realidade uma espécie d $\epsilon$ recenseamento, como se pode verificar compulsando êsses documentos coloniais e imperiais, recolhidos à secção histórica do Departamento do Arquivo do Estado.

Cumpre notar que há códices mais gerais e outros bem resumidos, porém com um denominador comum: trazem sempre o mapa geral da vila, dividida em bairros ou paróquias, com - número de habitantes, agrupados em "fogos", em ordem crescente de importância, pois, "fogo" n. ${ }^{0} 1$ é sempre o do "Capitão". Aquêles que não estão familiarizados com a nomenclatura histórica antiga, lembramos que cada "fogo" corresponde a um lar, isto é, uma família encabeçada pelo chefe, "sua imulher", filhos, agregados e escravos. Quase sempre, anexo ao códice da população, há um outro quadro estatístico com anotações em fôlhas separadas de brancos, mulatos livres, mulatos cativos, pretos livres e pretos escravos. Ainda informações de idade, estado civil, nascimentos e obitos. Alguns, trazem, o que é raro, lista de preços correntes naquele determinado mês e ano, com os gêneros importados, exportados e consumidos devidamente ànotados. E' excusado dizer que essas anotações são em português arcaico, com abreviaturas usuais e também danificadas pela humidade e pelos papirófagos, e por isso mesmo oferecem sérias dificuldades aos interessados.

A título de curiosidade, damos alguns exemplos:

1. - Num códice, em regular estado de conservação, datado de 1799, lê-se: 
"mapa geral dos Habitantes que existem na Parochia de Paranapanema, distrito de Itapetininga, em anno de 1799, suas occupaçoens, empregos, generos que cultivam e seos negocios".

Anexo: "Dos preços correntes na Parochia de Itapetininga no mês de Dezembro de 1799 ( 1 - generos de importação, 2 - generos de exportação, 3 - generos consumidos na Parochia)".

caixa 65 :

2. - Outro exemplo, catalogado e arquivado na mesma

"Lista geral dos habitantes da Villa de Itapetininga dondehé capitan mor Salvador deOliveira Leme no mez dejaneiro do anno do Senhor de 1777...".

3. - Ainda outro, do princípio do século XIX:

"Lista geral da primeira Comp.a das Ordenanças da Villa de Itapetininga em o presente anno (1808) Seos nomes, Empregos Naturalidades Idades Estados Cores Occupações cazualidades que acontecerão em cada hum das suas respectivas famílias desde a factura das listas do anno antecedente".

Há em seguida, separadas por colunas, encimadas pelas indicações das mais interessantes: 1a. coluna: (fogos), 2a. coluna:

1 - "O cap.m Salvador de Oliveira Ayres natural de V. de Sorucaba - D. Izabel da Conceição Smola, n.a da mesma. Filhos (8) com os nomes e idades; em baixo: escravos relacionados, além do nome, idade, também a procedência, exemplo: João Angola - Bárbara - Banguela; Manuel Congo.

Depois das colunas indicando cor, idade, estado civil de todos êles, a última é mais interessante pelo fato de mostrar:

"Occupações e Cazualidades:

"Agricultor colheo: milho, 500 alq.; feijão (nada tem anotado); arroz, 1 alq.; marcou bezerros, 22".

Ao lado anotações do filho, na última coluna:

Falta: "Falta o f. Manoel que está em Sorocaba com seo negocio de farinha sêca".

No fogo $n .^{\circ} 2$ :

"O Sarg. Mór João Afonso Pra. nat. de Sta. Maria do Salto", etc., etc.

E nas "Occupações e Cazualidades": 


\begin{abstract}
"Colheo - milho, 200 alq.; feijão, 30 alq.; arroz, 10 alq.; algodão, 16 alq.; mendoim, 5 alq.; marcou gado, 20 cabeças".

Tambem negocea com tripas.

Faltão os filhos João que foi o Rio com cobranças; Domingos e Manoel Leandro que forão p. Coritiba buscar gado".
\end{abstract}

Podemos afirmar que os dois exemplos acima indicados dizem bem do valor cultural dos maços de população, como também da característica econômica da região.

\title{
b). - Ofícios diversos.
}

A denominação de "Ofícios diversos" foi dada à correspondência entre a localidade e o govêrno da capitania e posteriormente da Província de São Paulo. Apesar do número, centenas de documentos manuscritos já foram vistoriados, catálogados e resumidos em fichas individuais, pelos funcionários da secção histórica, familiarizados com a leitura paleográfica e com a danificação sofrida (papirófagos, humidade, diluição da tinta, dado os processos primários de fabricação doméstica) por quase todos os documentos. Os originais estão recolhidos às caixas apropriadas (de alumínio) cuja numeração corresponde às fichas-resumos insertas no catálogo-chave, organizado pela própria secção.

Documentos que comprovam fatos ocorridos na própria localidade como: problema de alimentação; testemunho de falta de rendimentos; proposta de nomeações, estão catalogados sob essa rubrica. Documentos existem também oriundos da metrópole portuguêsa, como por exemplo: participação do nascimento de um novo membro da Casa rèinante ou mesmo donativos, provocados pelo terremoto que destruiu parte da cidade de Lisboa. Ei-los, na ordem em que foram anotados.

No maço 52 - encontramos um documento instrumentado $\mathrm{ccm}$ a seguinte indicação:

De quem - Araujo (Cap. mór Francisco Xavier do) Itapetininga, 13-3-1822.

A quem - Aos membros do governo.

Assunto - Ofício declarando que enviava quatro recrutas. Doc. 1. Maço 52. Pasta 3. N.o 96.

\section{Outra ficha sôbre indios.}

De quem - Leme (Salvador de Oliveira) Cap. mór de Itapetininga, 18-8-1793.

A quem - Ao govêrno da Capitania. 
Assunto - Sôbre a expulsão de 50 homens armados para a deligência contra os bugres, tendo o mesmo capitão-mór contribuido com 50 mil réis para a mesma expedição e que o farmacêutico Coronel Franc. Melo Flexa se achava doente motivo êste que demorou a expedição. Maço 52. Pasta 1. Doc. 7.

\section{Sôbre alimentação:}

De quem - Aguiar (José Francisco), Itapetininga, 24-6-1798.

A quem - Ao Sr. Coronel Luís Antônio Neves de Carvalho.

Assunto - Sôbre armazem do sal para a boa economia e distribuição do mesmo pela Câmara etc...

Maço 52. Pasta 1. N.o 51.

De quem - Ayres (Salvador de Oliveira) Cap. mór, Itapetininga, 9-2-1799.

A quem - Ao govêrno da Capitania.

Assunto $\rightarrow$ Sôbre mapas dos habitantes das paróquias desta vilà, etc. 1 documento.

Maço 52. Pasta 1. N.o 57.

Do maço 77 podemos citar o seguinte exemplo:

De quem - Câmara. Itapetininga, 22-11-1793.

A quem - Ao governador da Capitania.

Assunto - Sôbre o nascimento da Princesa da Beira.

Maço 77. Pasta 2. N.o 31.

De quem - Câmara. Itapetininga, 7-5-1798.

A quem - Ao governador da Capitania.

Assunto - Pedindo a remessa de 150 alqueires de sal, para atender às necessidades da população.

Maço 77. Pasta 2. N.o 39.

De quem - Câmara. Itapetininga, 14-2-1796.

A quem - Ao governador da Capitania.

Assunto - Que o Conselho (Câmara) da vila, não contava com rendimentos...

Maço 77. Pasta 2. Doc. 35.

De quem - Câmara. Itapetininga, 7-3-1784.

A quem - Ao governador da Capitania. 
Assunto - Propondo ao govêrno 3 pessoas: doutores José Vaz de Carvalho, João Moreira da Rocha e Antônio Caetano Alves para, dentre elas ser uma escolhida para o cargo de juiz das medições.

Maço 77. Pasta 2. Doc. 27.

De quem - Câmara. Itapetininga, 2-3-1796.

A quem - Ao governador da Capitania.

Assunot - Sôbre donativos para a reedificação da cidade de Lisboa.

Maço 77. Pasta 2. N.o 35.

\section{c). - Livros de Registro de terras.}

Os livros de registro de terras de Itapetininga, catalogados $\epsilon$ arquivados em separado no gabinete do chefe da secção histórica, correspondem a uma espécie de "arquivo secreto". Instrumentam títulos de propriedade de terra até 1889 e só são facultados à consulta direta pelos interessados mediante requerimento ao diretor do Departamento do Arquivo, podendo assim obter certidões negativas, devidamente autenticadas, mediante uma taxa.

\section{d). - Documentos manuscritos referentes à éra republicana.}

Catalogados na secção administrativa, nos mesmos moldes da secção histórica, isto é, fichas-resumo, referem-se mais especialmente à correspondência protocolada pela Secretaria de Educração do Estado. Certamente encerra elementos interessantes para a reconstituição da vida escolar de um dos mais famosos centros educacionais do Estado.

\section{2. - FONTES IMPRESSAS EXISTENTES NA BIBLIOTECA DO DEPARTAMENTO DO ARQUIVO DO ESTADO.}

$\mathrm{Na}$ Biblioteca do Departamento do Arquivo que, além de obras em geral, conta com uma das mais valiosas coleções de leis, relatórios e periódicos, assim como revistas e jornais, não encontramos nenhuma monografia sôbre Itapetininga. Além de artigos em obras gerais, merecem destaque jornais do passado imperial e da primeira fase republicana, abaixo discriminados, como também alguns exemplares de dois periódicos tri-semañais: Tribuna Popular, que tem como diretor o Dr. Alcino Monteiro de Barros Bertoldi e Aparecida do Sul, cujo atual diretor é o Sr. José Carvalho Salem. 
Dentre os jornais antigos merecem ser mencionados, em ordem cronológica: a). - Tribuna do Povo (1908) . b) . - 0 Demrocata (1908).

FONTES MANUSCRITAS EXISTENTES NOS ARQUIVOS PÚBLICOS E PARTICULARES DA PRóPRIA LOCALIDADE.

1). - ARQUIVOS PAROQUIAIS.

a). - Livro Ho Tombo.

A fonte informativa mais antiga de Itapetininga é o Livro do Tombo da Igreja Matriz de Nossa Senhora dos Prazeres, pois remonta êle a 1879 e vai até 1882 . Está recolhido no Arquivo da Cúria Diocesana de Sorocaba.

O primeiro têrmo do Livro do Tombo, que se encontra no Arquivo paroquial de Itapetininga, sob a responsabilidade do Vigário, o Venerando Cônego Luís de Almeida Morais, que reside nessa localidade desde 1956, data de 24 de agôsto de 1890 .

A criação da referida Paróquia remonta a 6 de novembro de 1771:

\begin{abstract}
"...Foi elevada a Vila e Paróquia a 6 de novembro de 1771 , o que se evidencia do fato de ser de 20 de janeiro de 1772 o primeiro assento de batismo nos livros da Paróquia, sendo seu primeiro Vigário o Padre Inácio de Araújo Teixeira...", "filho ilustre desta terra foi Dom Joaquim José Vieira, bispo do Ceará. A atual Matriz é obra do Vigário Padre Francisco de Assunção Albuquerque, falecido em 1878" (3).
\end{abstract}

b). - Livro de batizados.

Primeiro batizado: 20 de janeiro de 1722 .

Total de livros: 63 volumes.

Estado em que se encontram os livros número 1 e 2: quase ilegiveis; os demais: regulares e bons (4).

c). - Livro de crismas.

Primeiro têrmo: 21 de setembro de 1918.

Total de volumes: 5 .

Estado em que se encontram: regular.

(3). - Annuario da Diocese de Sorocaba. São Paulo, Escolas Profissionals do Lyceu Coração de Jesus, annos II e III, 1926-1927, págs. 11 e 12.

(4). - 0 livro n.० $16-1871$ a 1888 registra batizados só de escravos. 
d). - Livro de casamentos.

Primeiró têrmo: 26 de fevereiro de 1772 .

Total de volumes: 24 .

Estado em que se encontram: regular.

e). - Livro de proclamas.

Primeiro têrmo: 19 de junho de 1927.

Total de volume: 51 .

Estado em que se encontram: regular.

f). - Livro de óbitos.

Primeiro têrmo: 7 de abril de 1772 .

Total de volumes: 9 .

Estado em que se encontram: regular.

Uma observação entre outras: no livro de óbitos, datado de 24 de março de 1789 a 8 de junho de 1818 encontra-se o seguinte têrmo:

"Falecimento de Josefa de Almeida, mulher de Pedro Valente Ribeiro, com os sacramentos da Penitência e Unção, tendo de idade 80 anos e sem testamento, por ser pobre. Seu corpo por mim recomendado foi sepultado dentro da igreja e para constar fiz êste assento que assinei. Vigário Francisco de Godoy Coelho"

\section{g). - Assentamento de escravos.}

Considerando a estrutura social da época existem livros em que eram registrados apenas os escravos.

Batizados: 25 de fevereiro de 1772 a 10 de agôsto de 1805 . Casamentos: 13 de março de 1773 a 3 de maio de 1798 .

Óbitos: 25 de dezembro de 1771 a 28 de outubro de 1801 .

No livro de óbitos encontra-se o seguinte têrmo:

"Aos treze dias do mês de setembro de 1801 anos, nesta Freguesia, faleceu da vida presente com os sacramentos da Penitência e Extrema Uunção. Escravo braçal de José da Silva Pacheco - 25 anos pouco mais ou menos. Seu corpo foi sepultado no adro desta Matriz. Vigário José do Amaral Gurgel de Almeida".

\section{h). - Outros livros.}

Dentre as capelas de bairros, paróquias ou mesmo propriedades rurais vinculadas à jurisdição da Igreja Matriz de Itapetininga, merece destaque a Igreja Matriz do Bairro do Alambari, onde tivemos a oportunidade de compulsar o Livro do 
Tombo com assentamentos que remontam aos meados do século passado.

No livro de óbitos o primeiro têrmo é de 25 de agôsto de 1861 e informa que:

"Maria, sepultada dentro da Igreja Matriz, com 1 ano e 9 meses, filha de Manuel Celestino e de Ledorna Maria, faleceu de lombrigas no Bairro do Alambari".

$\mathrm{Na}$ mesma Igreja podem ser encontrados mais dois livros de assentamentos de óbitos, estado regular, encapados, rubricados, correspondentes ao período de 1783 a 1919 .

\section{2). - CARTÓRIO DE PRIMEIRO OFICIO.}

Localização: Avenida Peixoto Gomide.

O serventuário é o Sr. Joaquim de Aguiar e o Oficial Maior o Sr. Antônio Iared.

O Sr. Joaquim de Aguiar deu-nos muitas informações e nos facultou o acesso aos livros de Escrituras, Registros de Testamentos e outros mais.

a). - Livro de escrituras.

Primeiro Livro: 27 de fevereiro de 1773.

Total: 262 volumes.

Estado de conservação: bom:

No quinto volume, datado de 9 de março de 1810, acha-se o seguinte têrmo:

"Escritura de alforria e liberdade - Liberdade dada a Ana Mulata, filha de Maria Mina - escrava que prestou bons serviços".

b). - Livro registro de testamentos de Sarapuí.

Primeiro lịvo: 1879.

c). - Livro de escrituras de Sarapuí.

Nesse livro encontra-se o seguinte têrmo:

"Escritura de compra e venda que faz Pedro Sagalheva a Jesuíno de Cerqueira Corson, de um escravo de nome Bento pelo preço e quantia de $1.200 \$ 000$, como abaixo se declara:

O escravo tinha doze anos e tinha sido herdado por Pedro Sagalheva de súa mãe. - Sarapuí: Freguesia de Nossa Senhora das Dores de Sarapuí do Município de Itapetininga". 


\section{3). - CARTó́RIO DO SEGUNDO OFfCIO.}

Localização: Avenida Peixoto Gomide.

Este cartório tem como serventuário o Sr. Luís Antônio Neto Caldeira e Oficial Maior o Sr. José Bonifácio de Moura.

O livro de Notas mais antigo traz o têrmo de abertura de 12 de maio de 1893 .

Total: 172 volumes.

Estado: bom.

Ainda nos foi facultado a consulta dos processos de Inventários, sendo o mais antigo o de 1780 , em estado quase ilegível.

Em virtude da supressão da Comarca de Sarapuí, parte dos livros foram para o Cartório de Primeiro Ofício e parte para o de Segundo Ofício.

Tivemos oportunidade de compulsar ainda o livro de Notas dt. Sarapuí, havendo um total de 16 volumes.

4). - ARQUIVO DA PREFEITURA MUNICIPAL.

Localização: Praça Marechal Deodoro, 305.

$\mathrm{O}$ atual Prefeito é o Dr. José Ozi, que muito gentilmente nos permitiu a consulta de vários livros.

Verificamos que o primeiro Intendente da Prefeitura foi o Sr. Procópio de Almeida Leme.

Anexa existe uma biblioteca municipal; faltam coleções de jornais.

No Arquivo da Prefeitura tivemos oportunidade de compulsar os seguintes livros:

a). - Livro de atas.

A primeira ata refere-se à inauguração da 4a. Exposição Regional do Estado de São Paulo, em Itapetininga, e foi lavrada às 4 horas da tarde do dia 24 de junho de 1905 .

Um dos subscritores desta ata foi o sr. Júlio Prestes, seguido dentre muitos pelo.sr. Francisco A. Peixoto Gomide, cujo nome o Instituto de Educação reverencia.

Total: 11 volumes, de 1905 a 1957 .

b). - Livro de posturas.

Primeiro volume: 1908.

Total: 2 volumes.

Estado de conservação: bom.

c) - Livro de têrmos de posse.

Primeiro volume: 7 de junho de 1911. 


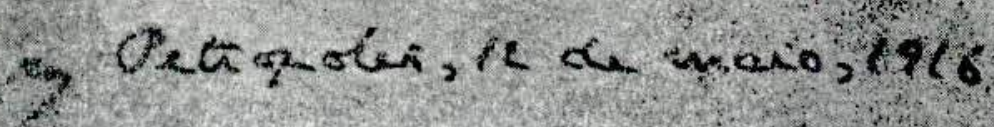

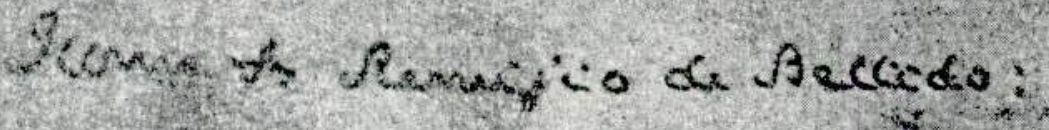

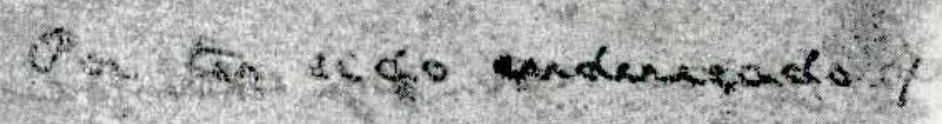

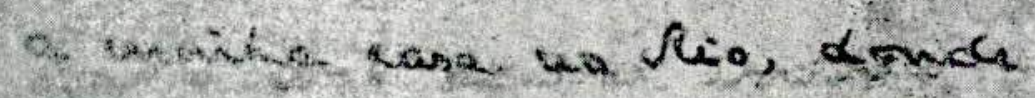

xun untes la quato megen, yo

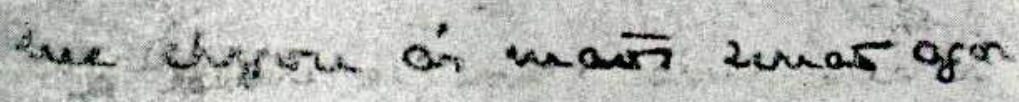

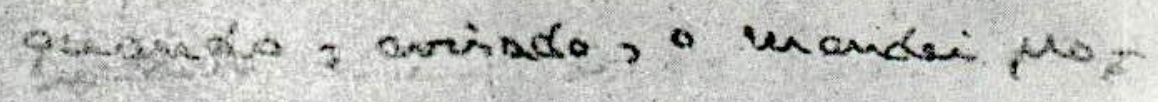

ervise, a can Gabacks dobe

gen $x$ a ne Gga.

reutto agadrey a vixi a 
obreguiar coin enfe exannela do

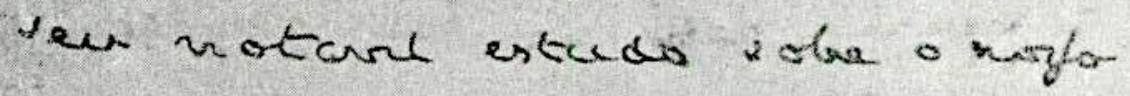
illuste historiador. I' cum eararico Literario, cujo rabor de vinyot à eouncidaraçor de guantor vaibsun

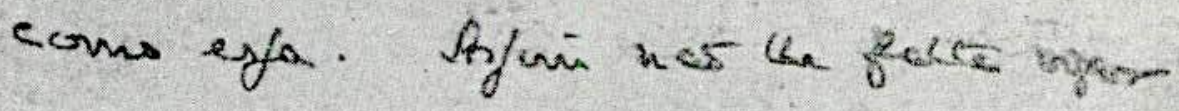

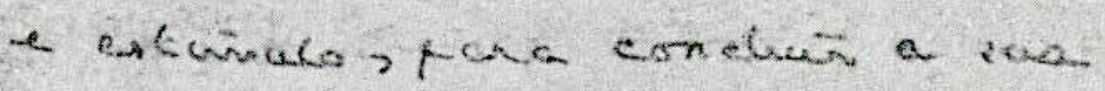

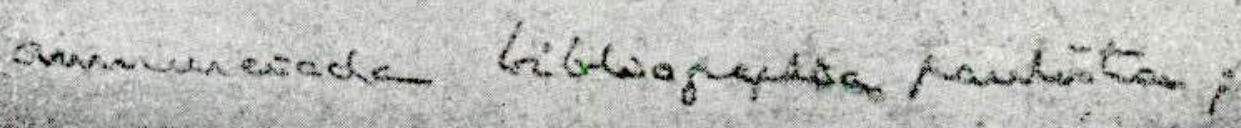


- Fená arguido ás lettan faties

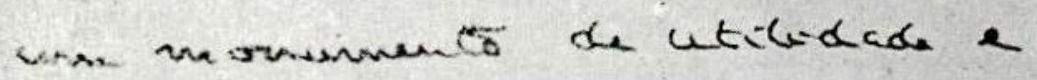
grandeye, gren nas houraná menor do yu a ellas o nome do antar de cuna obra tor pueviona.

re to act: o otr: w:

Rey arong 


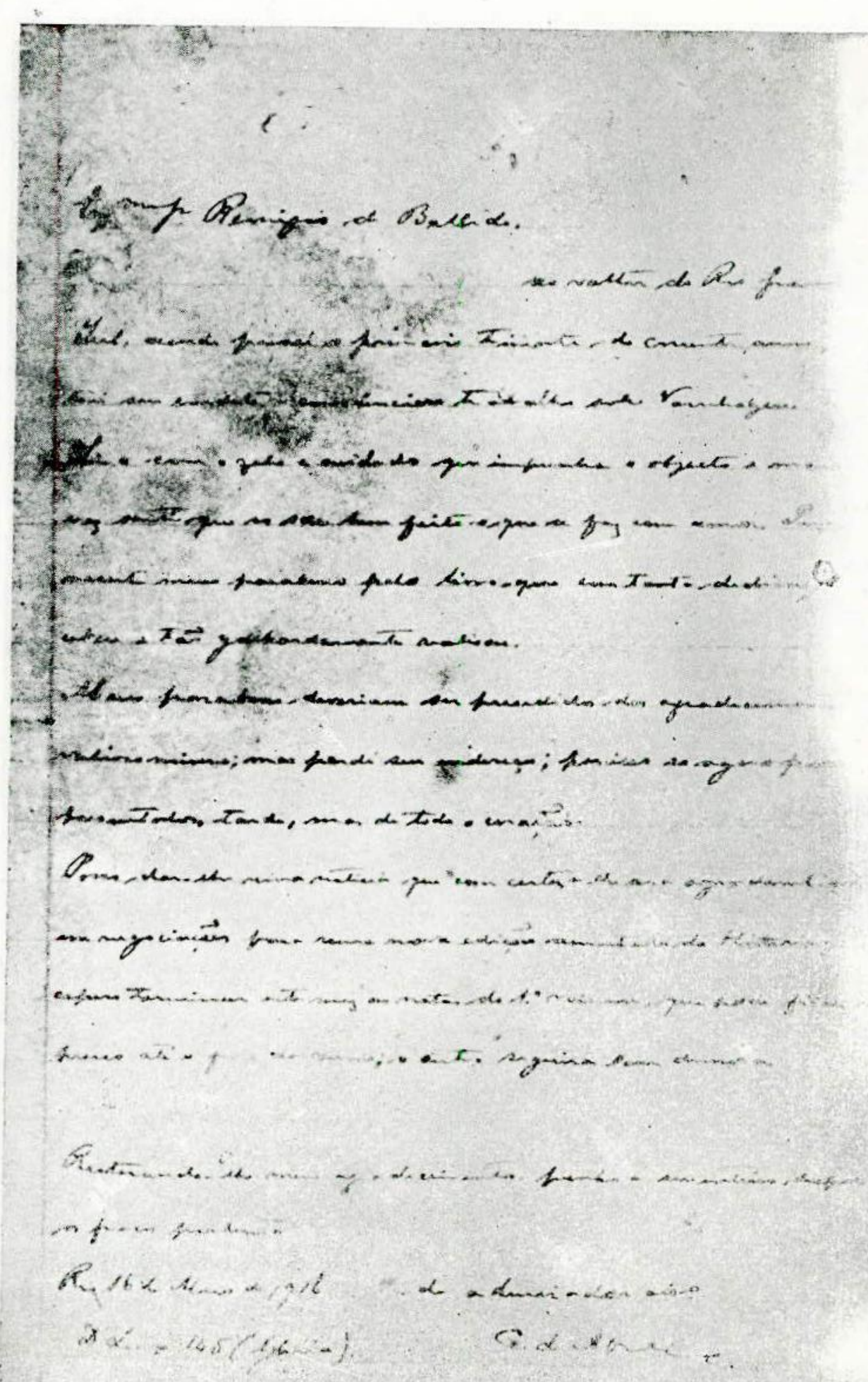


O primeiro têrmo refere-se à posse de um terreno municipal passado em favor do cidadão Silvestre de Carvalho Leitão.

d), - Livro ide lavratura dos contratos e registros dos contratos feitos com a Câmara Munlicipal.

Abertura: 27 de dezembro de 1912 .

O primeiro contrato registrado nesse livro foi feito entre José Giorgi e Doutor Manfredo Antônio da Costa com a Câmara Municipal de Itapetininga, referindo-se ao fornecimento de iluminação pública e particular e energia elétrica para a cidade e Município. Foi lavrado aos 3 de maio de 1910.

\section{e). - Livro de lecretos e nomeações.}

Primeiro volume: $1 .^{\circ}$ de agôsto de 1932.

Nele consta o Decreto n. ${ }^{\circ} 17$ que estabelece o preço para venda de pães comuns:

"Eu, Professor Antônio de Souza Melo, prefeito municipal dêste Municipio de Itapetininga, Estado de São Paulo, atendendo à situação anormal que atravessa o Estado, com o Movimento Constitucionalista e que, em periodo tal, necessárias se tornam medidas preventivas para que os gêneros de primeira necessidade não se encareçam e não seja, assim, sacrificada a população,

Decreto:

Art. $10^{\circ}$ - Os senhores padeiros dêste Município só poderão cobrar de cada quilo de pão comum, no máximo $1 \$ 100$.

Art. $2 .^{\circ}$ - Os pães de $\$ 100$ terão no mínimo 75 gramas de pêso.

Art. 3.0 - Aquêle que infringir o presente decreto, incorrerá na multa de $100 \$ 000$ a $500 \$ 000$, e, no caso de. reincidência, ser-lhe-á caçada a respectiva licença e fechado o negócio.

Art. 4.0 - Este decreto entrará em vigor na data de sua publicação, revogadas as disposições em contrário.

Secretaria da Prefeitura de Itapetininga, em 2 de agôsto de 1932 .

Eu, Benedito Melo Rocha, Secretário, escrevi".

Total: 3 volumes.

Estado de cosnervação: bom.

f). - Livro de portarias e nomeações.

Primeiro livro: 7 de fevereiro de 1941.

Total: 4 volumes.

Estado de conservação: bom. 
5). - ARQUIVO DA CÂMARA DOS VEREADORES.

Os funcionários encarregados de zelar pelos livros manuscritos e demais documentos são: o Dr. José de Melo Leonel e o Sr. José Emílio Pinto Nestri.

a). - Livro de atas das sessões da Câmara.

Primeiro livro: 28 de fevereiro de 1843.

Primeira ata: Presidência do Doutor Pereira Chaves. Teve leitura um requerimento de vários moradores do Bairro da Chapada, queixando-se de Maria Pires e seu genro Bento Soares, por terem fechado uma restinga de mato e aguada pública de que se serviam os ditos moradores.

Total: 25 volumes.

b). - Livro de receitas e despesas.

Primeiro livro: 1940.

6): - CARTóRIO DE REGISTRO E HIPOTECAS.

Localização: Avenida Peixoto Gomide.

O serventuário é o Dr. Tercis de Melo Almada e o Oficial Maior o Sr. Josué da Silva Neto.

a). - Livro de registro de imóveis - transcrição dos imóveis. Abertura: 20 de abril de 1867. Juiz que rubricou: Antônio Pinto da Silva Vale, Oficial Maior João Monteiro de Carvalho.

Primeiro registro: 11 de abril de 1867.

Total de volumes: 47 .

Estado de conservação: bom.

b) . - Livro de registro de hipotecas.

Primeiro registro: $1^{\circ}$ de março de 1891.

Juiz: Antônio Pinto da Silva Vale, Oficial Maior Benedito Rolim de Oliveira.

Total: 6 volumes.

Estado de conservação: bom.

c). - Processos.

Rol dos culpados do Juízo de Direito lda Comarca de Itapetininga.

Primeiro volume: 1863, onde pudemos anotar o que vai abaixo discriminado; primeiro réu: Antônio José de oliveira. 10 de junho de 1864 .

Foi absolvido por sentença de 29 de setembro de 1874 pelo Juiz de Direito da Comarca José Carlos Machado d'Obra. 
Segundo volume: 1878.

Primeiro réu: Antônio, escravo de Salvador Rolim. 22 de fevereiro de 1877 (5).

Quarto volume: 6 de maio de 1903 .

Quinto volume: 9 de outubro de 1923.

Estado de conservação: bom.

d). - Livros de atas do Júri.

Primeiro livro: abertura 25 de junho de 1834 .

Primeira sessão do Juri: 5 de julho de 1834.

Segundo volume: 20 de abril de 1859 .

Os volumes seguintes datam de 1866, 1870, 1876, 1882, 1792, sendo o oitavo volume de 1895 . Todos em bom estado.

e) . - Protocolo das audiências do juízo ldas execuções criminais. Juiz: Gabriel Gomide.

Primeira audiência: 25 de março de 1893.

Segundo volume: 15 de junho de 1901 .

Terceiro volume: 5 de abril de 1911 a 13 de abril de 1912 .

Quarto volume: 1922. Transcrição das Atas de Instalação € da Eleição de Presidente e Vice-Presidente da República.

Sexto volume: 1930 .

Estado de conservação: bom.

\section{7). - CARTÓRIO DE PAZ DO PRIMEIRO DISTRITO.}

O Município consta de dois Distritos de Paz: O Distrito de Paz de Nossa Senhora dos Prazeres e o Distrito de Aparecida do Sul.

O Cartório do Distrito de Nossa Senhora dos Prazeres está instalado na Rua Silva Jardim, 245, sendo seu responsável a senhora Juventina Silveira Ramos e Oficial Maior a senhora.Walkíria Silveira Ramos.

a). - Livro de nascimentos.

Primeiro livro: abertura em 30 de novembro de 1888 .

Primeiro têrmo: $10^{\circ}$ de janeiro de 1889.

Distrito de Paz de Nossa Senhora dos Prazeres, Municipio de Itapetininga, Província de São Paulo, nasceu no dia 30 de setembro de 1888 Péricles Galvão, filho de Antônio Galvão e Antônia Galvão (artistas).

Total de volumes: 62 .

Estado de conservação: bom.

(5). - Ignora-se o paradeiro do 3.0 volume. 
b). - Livro de casamentos.

Primeiro livro: abertura em 20 de maio de 1890.

Primeiro têrmo: 28 de junho de 1890. José Machado de Albuquerque e Isabel Maria Vieira.

Total de volumes: 28 , todos em bom estado.

c) : - Livrio de óbitos.

Primeiro livro: abertura em 30 de novembro de 1888 .

Primeiro têrmo: 17 de janeiro de 1889. Antônio Mariano da Silva, 4 meses, filho de Joaquim Mariano da Silva e Benvinda Maria do Espírito Santos, morreu de febre.

Total: 27 volumes.

Estado de conservação: bom.

8). - CARTóRIO DISTRIBUIDOR, CONTADOR, AVALIADOR E PARTIDOR.

Localização: Avenida Peixoto Gomide.

O serventuário é o Sr. João Jacinto de Moura e o Oficial Maior o sr. Célio Simões.

a). - Livro de escrituras.

Segundo livro: 6 de abril de 1896 .

O segundo livro inicia-se com o número de ordem 167. Anota o processo de troca de uma casa por metade de outra no. valor de 1.200 réis, entre o Sr. Capitão João Francisco Soares e sua mulher, cuja continuidade os interessados poderão diretamente verificar.

Total: 21 volumes.

Estado de conservação: bom.

9). - CARTóRIO DE PAZ DO SEGUNDO DISTRITO.

O Cartório de Paz do Distrito de Aparecida do Sul acha-selocalizado na Rua dos Expedicionários Itapetininganos, 839, sendo seu responsável o Sr. João Carlos de Oliveira.

a). - Livro de nascimentos.

Primeiro livro: abertura em 30 de novembo de 1934 .

Primeiro registro: 4 de dezembro de 1934 José Roberto Primo, filho de Humberto Primo e Dona Sílvia Vilaça Primo.

Total: 21 volumes.

Estado de conservação: bom.

b). - Livro especial de nascimentos - registro de adultos. Abertura em 16 de outubro de 1942.

Total: 1 volume em bom estado de conservação. 
c). - Livro de casamentos.

Primeiro livro: abertura em 29 de novembro de 1934 .

Primeiro têrmo: Antônio Fagnani e Dona Joana Barco, 5 de janeiro de 1935 .

Total: 14 volumes.

Estado de conservação: bom.

d). L Livro de óbitos.

Primeiro livro: primeiro têrmo -7 de dezembro de 1934 . Alcindo Coelho, 2 meses de idade.

Total: 9 volumes.

Estado de conservação: bom.

e). - Editais e proclamas.

Primeiro livro: abertura em 29 de novembro de 1934.

Primeiro têrmo: Antônio Fagnani, transcrito em 15 de dezembro de 1934.

Total: 5 volumes.

Estado de conservação: bom (6) .

a). L Livro de nascimentos.

Primeiro livro: abertura em 6 de janeiro de 1914 .

Primeiro têrmo: 22 de janeiro de 1914. Rui, filho de Martiniano Pires de Andrade e de dona Zulmira Maria de Jesus.

Total: 9 volumes.

Estado de conservação: bom.

b) . - Livro de casamentos.

Primeiro livro: abertura em 6 de janeiro de 1913.

Primeiro têrmo: 20 de fevereiro de 1914. Pedro Elias de Oliveira e dona Bertolina Pereira Nunes.

Total: 3 volumes.

Estado de conservação: bom.

c). - Livro de óbitos.

Primeiro livro: abertura em 6 de janeiro de 1914 .

Primeiro têrmo: 23 de maio de 1914. Luís, de 2 anos de iỏade, filho de Sezenando Boava de Resende e dona Zelina Maria dos Prazeres.

Total: 4 volumes.

Estado de conservação: bom.

(6). - Para êste Cartório foram transferidos os livros do ex-Distrito de Paz de Morro Alto. 


\section{d). - Livro de editais.}

Primeiro livro: abertura em 6 de janeiro de 1914 .

Primeiro têrmo: 4 de fevereiro de 1914. Pedro Elias de Oliveira.

Total: 3 volumes.

Estado de conservação: bom.

\section{CONCLUSÃO.}

As notas acima discriminadas, ainda incompletas, e como o próprio nome indica, nada mais são do que uma tentativa de contribuir, modestamente, na linha da primeira etapa de um trabalho erudito, sôbre o passado histórico de um dos mais cultos e tradicionais municípios paulistas: Itapetininga - que desejaríamos, e muito, ver realizado por um de seus filhos, quer seja em caráter particular ou com o beneplácito das autoridades civis e eclesiásticas da própria localidade.

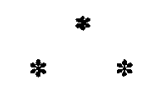

\section{BIBLIOGRAFIA.}

1). - Obras gerais e específicas.

IBGE. - Enciclopédia dos Municípios Brasileiros. Rio de Janeiro, 1951. Vol. XXVIII, págs. 446 a 450.

Caldeira (João Netto). - Álbum de Itapetininga. São Paulo, 1934. Organização Cruzeiro do Sul.

Galvão Júnior (Antônio). - Itapetininga e sua história. São Paulo, 1956. Gráfica Biblos Ltda.

Almeida (Antônio Paulino). - Pequeno Prontuário do Departamento do Arquivo do Estado. São Paulo.

2). - Periódicos.

Annuário da Diocese de Sorocaba. Sáo Paulo, 1926 e 1927. Anos II e III. Escolas Profissionais do Liceu Coração de Jesus.

Rodrigues (Maria Regina da Cunha). - Arrolamento das fontes primárias sôbre Laranjal Paulista e regiấo circunvizinha. In "Revista de História". São Paulo, 1959, n.ำ 39, págs. 209-215.

Rodrigues (Maria Regina da Cunha). - Jornais antigos existentes no Departamento do Arquivo do Estado. In "Revista de História". São Paulo; abril-junho, 1960, n. ${ }^{0} 42$, págs. 493-507. 
Almeida (Aloísio). - Itapetininga, in jornal "O Correio Paulistano". São Paulo, edição de 14 de julho de 1954.

Itapetininga, a Atenas do Sul, in nota de redaçăo do jornal.

"O Diário de São Paulo". São Paulo, edição de 3 de junho" de 1950 .

\section{Fontes Manuscritas.}

As fontes manuscritas, em sua quase totalidade fontes primárias . básicas, tanto para o arrolamento destas notas prévias, como para: instrumentar a eventual elaboração de uma monografia sôbre a históri do município de Itapetininga, em bases científicas, encontra-se quase tôda inédita, na seç̧ão histórica do Departamento do Arquivo.s do Estado e nos arquivos públicos e particulares de Itapetininga, acima citados.

YARA CECÍLIA COSTA SPOSATTK Aluna do Curso de História da Faculdade de Filosofia,... Ciências e Letras Sāo Bento, da Pontifícia Universidade: Católica de São Paulo 